\title{
Assessment Rates and Causes of Readmissions in Military Casualties
}

\section{Hamid Reza Gharehchahi}

Baqiyatallah University of Medical Sciences https://orcid.org/0000-0003-3422-3707

\section{Sadrollah Mahmoudi ( $\triangle$ mahmoudisadrollah@gmail.com )}

Emergency Department, Baqiyatallah 9 University of Medical Sciences, Tehran, Iran

Hadi Khoshmohabat

Baqiyatallah University of Medical Sciences

Hamid Reza Javadzadeh

Baqiyatallah University of Medical Sciences

Amin Mohamadrezapourzare

Baqiyatallah University of Medical Sciences

\section{Research}

Keywords: Combat Trauma, Readmission, Rehospitalization, Injury, Complications

Posted Date: February 15th, 2021

DOl: https://doi.org/10.21203/rs.3.rs-227193/v1

License: (c) (1) This work is licensed under a Creative Commons Attribution 4.0 International License. Read Full License 


\section{Assessment rates and causes of readmissions in military casualties}

2 Hamid Reza Gharehchahi ${ }^{1}$, Sadrollah Mahmoudi ${ }^{2 *}$, Hadi Khoshmohabat ${ }^{1}$, Hamid Reza

3 Javadzadeh $^{1}$, Amin Mohamadrezapourzare ${ }^{1}$

1. Trauma Research Center, Baqiyatallah University of Medical Sciences, Tehran, Iran

2. Emergency Department, Baqiyatallah University of Medical Sciences, Tehran, Iran

"Corresponding author: Sadrollah Mahmoudi ${ }^{1}$, Emergency Department, Baqiyatallah

10 University of Medical Sciences, Tehran, Iran

11 Phone/Fax: 00982188053766, E-mail address: Mahmoudisadrollah@gmail.com

\section{Abstract}

Introduction: Military medical care encompasses domains such as the long-term prognosis, morbidity, and quality of life of survivors after discharge from the hospital. The identification factors affecting hospitalization and readmissions are crucial in military settings. The study aimed to assess rates and causes of readmissions in military casualties.

20 Methods: We included 775 military personnel with combat-related injuries from September 2014

21 to October 2019. We determined readmissions if they occurred within one year since the date of

22 discharge from the index admission. The data was included regarding the pattern and mechanism

23 of injury, Abbreviated Injury Scale (AIS), injury severity score (ISS), primary and subsequent

24 treatments and procedures, experienced side effects, source of admission, hospital care unit, and

25 the length of stay in the hospital.

26 Results: The mean age of the patients was $27.99 \pm 7.55$ years. The great majority of the investigated

27 combat-related injuries were penetrating $(\mathrm{N}=639,82.5 \%)$, followed by blunt $(\mathrm{N}=97,12.5 \%)$. The

28 most injured part of the body was the extremities ( $\mathrm{N}=360,46.5 \%)$, followed by the head and neck

$29(\mathrm{~N}=175,22.6 \%)$ and the abdomen and pelvis $(\mathrm{N}=106,13.7 \%)$. The most common reason for the

30 readmission event number 1-7 was overall wound infection. The average length of hospitalization 
31 during the index admission was $9.48 \pm 12.07$ days. There was a significant relationship between

32 multiple readmissions and total readmission days and LOS, max AIS, ISS, side effects, and blood

33 transfusion $(\mathrm{P}<0.001$ for all the variables). Among the variables influencing multiple readmissions,

34 ISS $>24$ led to the highest risk.

35 Conclusion: A longer LOS within the index admission and its associated factors put patients at

36 risk of multiple and longer readmission events in the future. The outcomes imply that patients with

37 more severe injuries may require high-quality care for longer durations as part of the initial hospital

38 inpatient stay, and this may motivate more effective management of combat-related injuries and

39 the associated medical costs.

41 Keywords: Combat Trauma; Readmission ; Rehospitalization; Injury; Complications

\section{Introduction}

44 During the past decades, along with the development and use of increasingly more dangerous

45 weapons in wars, there have been some advances in military medical care leading to life-saving

46 treatments and better outcomes for combat-related injuries (1). Management of traumatic combat

47 injuries is primarily focused on reducing casualties. Over time, it is also being expanded into areas

48 such as the long-term prognosis, morbidity, and quality of life of survivors after the initial

49 discharge from the hospital. Currently, there is a need for developing new strategies to improve

50 prognosis and reduce morbidity experienced by wounded military personnel. This necessitates

51 careful assessment of the quality of medical care received during the first admission, identification

52 of factors adversely impacting this quality, and the design of medical and nursing interventions

53 which are crucial for the development of good-quality services. 
54 In terms of quality assessment, various indices have proved useful in both civilian and military

55 settings, including the length of the first stay in the hospital (LOS), experienced side effects, and

56 readmission rate $(2,3)$. The first index, LOS, is widely used to evaluate the degree of efficiency of

57 hospital care $(4,5)$. Many incentive schemes have been introduced to encourage hospitals to

58 decrease LOS (5), although significant reduction plans should be implemented cautiously as rapid

59 hospital discharge before ensuring the patient's medical stability might increase readmission rates

60 in the long run (4). This complicates the justification of interventions for considerably shortening

61 LOS. On the other hand, the readmission rate provides a more promising index of the quality of

62 hospital care (5). By definition, readmission is a hospital admission event within at least one month

63 of the initial admission (6). Readmissions are common (7) and more likely to be associated with a

64 poor quality of hospital care (8). Readmission rate is also deemed important from an economic

65 standpoint (9); readmissions highly utilize hospital financial resources and may place an additional

66 cost burden on patients and their families $(4,7)$. Furthermore, they can affect other members of

67 society by preventing them from receiving their required hospital care. Consequently, a high

68 readmission rate is also a cause for concern in military settings. Many military health providers

69 around the world set a goal to reduce the overall rate of readmission events (10). There is a body

70 of research about readmission and its associated factors about trauma patients in civilian practice.

71 However, as civilian and military trauma injuries are entirely different from each other based on

72 the patterns of injury, complexity of wounds, and pathophysiologic consequences, such data may

73 not be useful in the military setting (11). Readmission events in military practice may correspond

74 to various independent variables which can be analyzed using statistical methods. Thus, war

75 wounds should be especially investigated and understood in terms of epidemiology,

76 characterization, and mechanism of injury. A full description of the medical, surgical, and nursing 
77 needs of wounded military personnel during index admission and their possible re-hospitalization,

78 as well as the analysis of this information, might provide a solid basis for comparing patient groups.

79 Such assays may help identify the subgroups that are more susceptible to multiple readmissions,

80 discover the main contributors to readmission, and assist modern hospital systems in addressing

81 these issues.

82 Historically, little published information is available about the epidemiology of injuries sustained

83 in combat $(8,12,13)$, and little is known about the main contributory factors in military re-

84 hospitalization. To the best of our knowledge, such resources are scarcely available about wars

85 occurring in the Middle East. Thus, given the importance of identifying major contributors to

86 readmission in the military setting, herein, we investigated the factors associated with multiple

87 readmissions and total days of readmission among patients with traumatic combat injuries for the

88 first time in Iran. The identification of these factors will lead to the formulation of better strategies

89 for meeting particular patient needs and helping patients with their full recovery. Therefore, in

90 addition to reducing the total number of readmission events by preventing potentially avoidable

91 readmissions, patients' quality of life can be improved. This study presents a description and

92 analysis of the results of investigating readmission events among wounded military personnel at a

93 military hospital in Iran by performing logistic regression analysis. It was assumed that the number

94 of readmission events and the total days of readmission might be influenced by factors such as the

95 pattern and mechanism of injury, required treatments and procedures, and LOS.

\section{Methods}

\section{Study population}

98 This study was conducted in a military hospital in Iran. The data were collected from military

99 personnel with combat-related injuries from September 2014 to October 2019 who had been 
100 transferred to the hospital for receiving initial care. The patients were then followed-up for a year

101 in terms of readmission. The data, including the patients' demographic information (age, sex, and

102 nationality), the year of admission event, medical history (comorbidities categorized based on the

103 International Classification of Disease, $10^{\text {th }}$ Revision, Clinical Modification [ICD-10-CM] codes)

104 as defined in the literature (14), information about trauma injuries and hospital care, discharge

105 disposition, and possible readmissions, were extracted from the patients' medical records and

106 collected through the ongoing observational cohort study. The data about trauma injuries and

107 hospital care included the pattern and mechanism of injury, injury severity score (ISS),

108 Abbreviated Injury Scale (AIS), primary and subsequent treatments and procedures (such as

109 operation), source of admission (such as the emergency room), experienced side effects, hospital

110 care unit (such as the critical care unit), and the LOS. The collected data on readmissions included

111 the reason for subsequent admission(s), the number of total readmission events, the LOS during

112 readmission, the relationship between the first readmission and the index admission (if any), and

113 the interval between the first readmission and the index admission. The Institutional Review Board

114 of the hospital and the associated university of medical sciences approved this study.

115 We determined readmissions if they occurred within one year since the date of discharge from the

116 index admission. Admissions more than a year after an index admission discharge date was not

117 regarded as readmission. Furthermore, the first admission events were included in the study only

118 if there was at least one further admission event during the follow-up period, i.e., a year. The index

119 admissions were excluded if the patient was referred to a hospital other than the index hospital for

120 any readmission event, or if the patient passed away during the follow-up period.

121 Based on the definition provided by the Association for the Advancement of Automotive

122 Medicine, the AIS is "an anatomically based, consensus derived, global severity scoring system 
123 that classifies an individual injury by body region according to its relative severity on a 6 point

124 scale (1=minor and 6=maximal)" (15). The part of the body that received the maximum AIS was

125 considered as the injured part of the patient's body. The ISS is an anatomical scoring system which

126 yields an overall score for patients who have multiple injuries (16). Moreover, the LOS was

127 defined as the number of days since patient admission or readmission until discharge, and was

128 calculated as the time of discharge minus the time of admission or readmission in hours, divided

129 by 24 . In addition, the total days of readmission was calculated by adding the number of days spent

130 in the hospital during each readmission event. The type of trauma was defined as penetrating,

131 blunt, and other types. The mechanism of trauma was also defined as fragments from explosive

132 munitions, bullets fired by a gun, blast, burns, and others. The definition of other independent

133 variables was obvious.

\section{Statistical analysis}

135 The association of variables of interest with multiple readmissions and total days of readmission

136 was investigated using logistic regression. With respect to the number of readmissions and total

137 days of readmission, the patients were classified into two categories: patients with a single

138 readmission and those with multiple readmissions, and patients with 1-7 day(s) and those with $>7$

139 days of re-hospitalization, respectively. In terms of categorical predictors which had more than

140 two levels, one of the subgroups was taken as the reference group with which the other groups

141 were compared. A Pearson chi-square contingency table analysis was performed to test the

142 relationships among qualitative variables. All the statistical analyses were performed in SPSS for

143 Windows, version 11.5 (IBM, Armonk, NY). P-values of $<0.05$ were deemed statistically

144 significant. 
146 Overall, 775 eligible patients were included and 431 patients had a single readmission, while the 147 rest, i.e., 344, experienced more than one readmission event within a year. The frequency of 148 patients based on the number of readmission events is given in Figure 1.

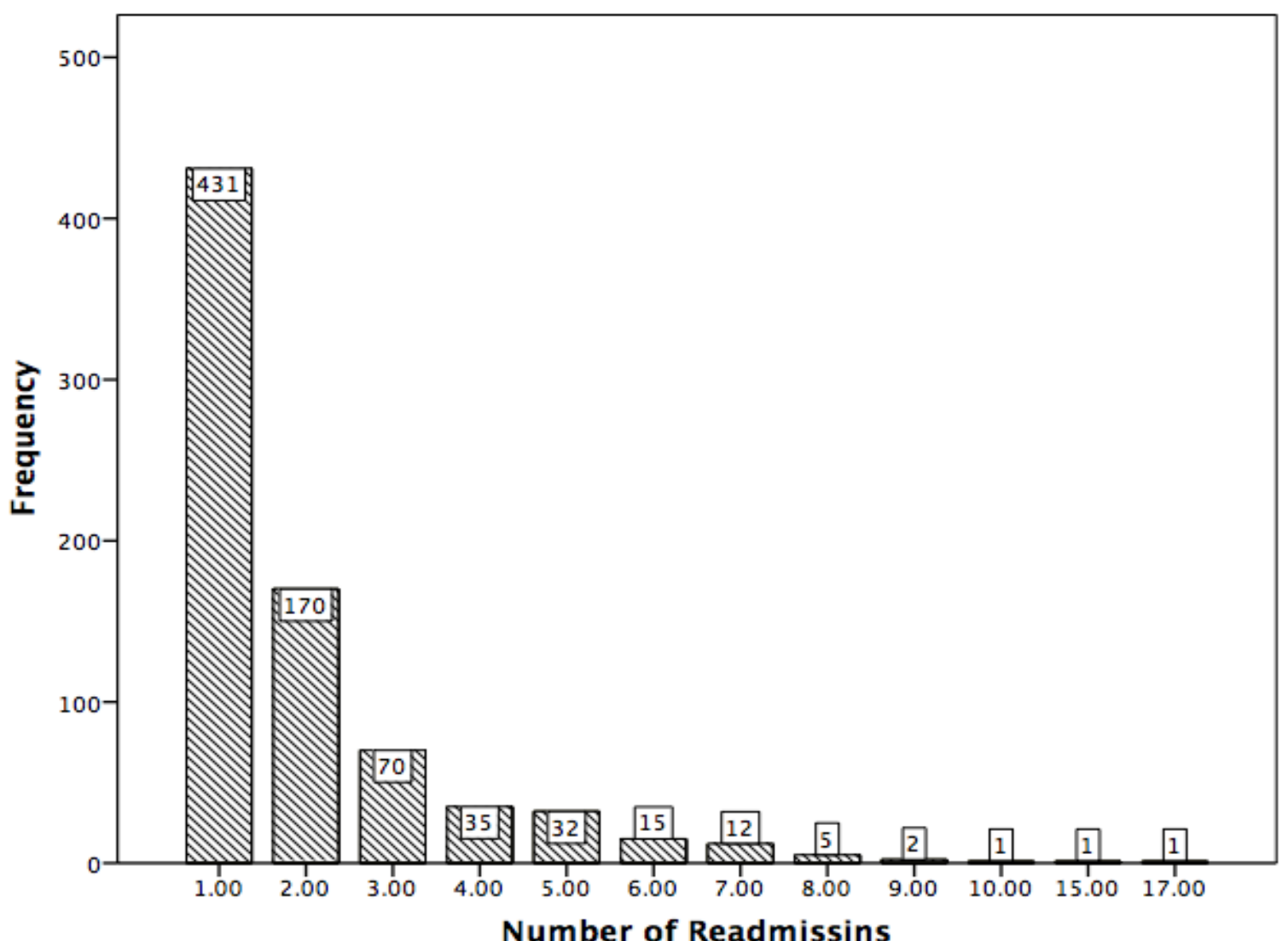

155 The mean age of the patients was $27.99 \pm 7.55$ years. Of the 775 patients enrolled, only two had a

156 positive history of addiction, and 10 patients were current smokers. The number of patients

157 admitted in 2014, 2015, 2016, 2017, 2018, and 2019 was 81, 277, 233, 141, 36, and 7, respectively.

158 In the vast majority of the final cohort of patients, no comorbid condition was reported $(\mathrm{N}=757)$, 
159 and only $2.33 \%$ demonstrated $1-3$ comorbid condition(s).

160 The most common reason for the readmission event number 1-7 was overall wound infection,

161 while the second most prevalent cause of hospitalization differed among readmission groups.

162 Table 1 represents detailed data about the reason for readmission event number 1-7. For the $8^{\text {th }}$

163 readmission event, the patients were frequently admitted because of pain, but the common cause

164 of re-hospitalization 9-15 was bedsores (data not shown in the table as the number of patients was

$165<10$ in each group).

166

167

168

169

170

171

172

173

174

175

176 


\section{Table 1. The reason for readmission for readmission numbers 1 -7th.}

\begin{tabular}{|c|c|c|c|c|c|c|c|c|c|}
\hline Reason & 1 & 2 & 3 & 4 & 5 & 6 & 7 & $\begin{array}{l}\text { Sum in } 1-7 \text { th } \\
\text { Readmission }^{\mathrm{A}}\end{array}$ & $\begin{array}{l}\text { Sum in all } \\
\text { Readmission } \\
\text { Groups }^{A}\end{array}$ \\
\hline Wound infections & 101(13) & $50(15.2)$ & $31(18.8)$ & $18(18.6)$ & $14(21.2)$ & $8(25)$ & $6(28.6)$ & 230 & 232 \\
\hline Gastrointestinal & $25(3.2)$ & $11(3.3)$ & $4(2.4)$ & $3(3.1)$ & $2(3)$ & $0(0.0)$ & $0(0.0)$ & 45 & 45 \\
\hline $\begin{array}{l}\text { Amputation stump } \\
\text { complications }\end{array}$ & $14(1.8)$ & $7(2.1)$ & $5(3)$ & $3(3.1)$ & $1(1.5)$ & $1(3.1)$ & $0(0.0)$ & 31 & 31 \\
\hline Movement restrictions & $64(8.3)$ & $27(8.2)$ & $14(8.5)$ & $6(6.2)$ & $2(3)$ & $1(3.1)$ & $1(4.8)$ & 115 & 115 \\
\hline $\begin{array}{l}\text { Deformity in head and } \\
\text { neck }\end{array}$ & $63(8.1)$ & $31(9.4)$ & $17(10.3)$ & $12(12.4)$ & $9(13.6)$ & $7(21.9)$ & $4(19)$ & 143 & 143 \\
\hline After care for surgery & $10(1.3)$ & $5(1.5)$ & $0(0.0)$ & $0(0.0)$ & $0(0.0)$ & $0(0.0)$ & $0(0.0)$ & 15 & 15 \\
\hline Respiratory & $7(0.9)$ & $2(0.6)$ & $1(0.6)$ & $1(1)$ & $1(1.5)$ & $0(0.0)$ & $0(0.0)$ & 12 & 12 \\
\hline Ophthalmic & $13(1.7)$ & $7(2.1)$ & $3(1.8)$ & $2(2.1)$ & $2(3)$ & $0(0.0)$ & $0(0.0)$ & 28 & 28 \\
\hline New trauma & $18(2.3)$ & $5(1.5)$ & $0(0.0)$ & $0(0.0)$ & $0(0.0)$ & $0(0.0)$ & $0(0.0)$ & 23 & 23 \\
\hline Graft & $32(4.1)$ & $13(4)$ & $8(4.8)$ & $5(5.2)$ & $2(3)$ & $0(0.0)$ & $0(0.0)$ & 60 & 60 \\
\hline Hearing & $24(3.1)$ & $8(2.4)$ & $3(1.8)$ & $0(0.0)$ & $0(0.0)$ & $0(0.0)$ & $0(0.0)$ & 35 & 35 \\
\hline Foreign Body & $52(6.7)$ & $20(6.1)$ & $9(5.5)$ & $3(3.1)$ & $2(3)$ & $0(0.0)$ & $0(0.0)$ & 86 & 86 \\
\hline Osteomyelitis & $6(0.8)$ & $2(0.6)$ & $2(1.2)$ & $0(0.0)$ & $0(0.0)$ & $0(0.0)$ & $0(0.0)$ & 10 & 10 \\
\hline Urinary & $8(1)$ & $5(1.5)$ & $3(1.8)$ & $2(2.1)$ & $2(3)$ & $0(0.0)$ & $0(0.0)$ & 20 & 20 \\
\hline Closure of ostomi & $18(2.3)$ & $7(2.1)$ & $4(2.4)$ & $3(3.1)$ & $2(3)$ & $1(3.1)$ & $0(0.0)$ & 35 & 35 \\
\hline Bedsore & $15(1.9)$ & $6(1.8)$ & $4(2.4)$ & $3(3.1)$ & $3(4.5)$ & $2(6.3)$ & $2(9.5)$ & 35 & 46 \\
\hline $\begin{array}{l}\text { Deep vein thrombosis } \\
\text { (DVT) }\end{array}$ & $7(0.9)$ & $5(1.5)$ & $3(1.8)$ & $3(3.1)$ & $3(4.5)$ & $1(3.1)$ & $1(4.8)$ & 23 & 23 \\
\hline Laryngopathy & $2(0.3)$ & $0(0.0)$ & $0(0.0)$ & $0(0.0)$ & $0(0.0)$ & $0(0.0)$ & $0(0.0)$ & 2 & 2 \\
\hline Neurologic & $6(0.8)$ & $4(1.2)$ & $2(1.2)$ & $1(1)$ & $0(0.0)$ & $0(0.0)$ & $0(0.0)$ & 13 & 13 \\
\hline Cardiologic & $2(0.3)$ & $2(0.6)$ & $1(0.6)$ & $1(1)$ & $1(1.5)$ & $1(3.1)$ & $1(4.8)$ & 9 & 9 \\
\hline Surgical device remove & $70(9)$ & $19(5.8)$ & $9(5.5)$ & $5(5.2)$ & $5(7.6)$ & $3(9.4)$ & $2(9.5)$ & 113 & 114 \\
\hline Pain & $75(9.7)$ & $34(10.3)$ & $18(10.9)$ & $14(14.4)$ & $9(13.6)$ & $4(12.5)$ & $3(14.3)$ & 157 & 161 \\
\hline Non-union of fracture & $64(8.3)$ & $19(5.8)$ & $7(4.2)$ & $1(1)$ & $0(0.0)$ & $0(0.0)$ & $0(0.0)$ & 91 & 91 \\
\hline Vascular & $8(1)$ & $2(0.6)$ & $1(0.6)$ & $0(0.0)$ & $0(0.0)$ & $0(0.0)$ & $0(0.0)$ & 11 & 11 \\
\hline Psychiatric & $34(4.4)$ & $23(7)$ & $9(5.5)$ & $7(7.2)$ & $5(7.6)$ & $2(6.3)$ & $0(0.0)$ & 80 & 80 \\
\hline Wound unhealing & $28(3.6)$ & $12(3.6)$ & $7(4.2)$ & $4(4.1)$ & $1(1.5)$ & $1(3.1)$ & $1(4.8)$ & 54 & 54 \\
\hline Hernia & $9(1.2)$ & $3(0.9)$ & $0(0.0)$ & $0(0.0)$ & $0(0.0)$ & $0(0.0)$ & $0(0.0)$ & 12 & 12 \\
\hline Total & $775(100)$ & $329(100)$ & $165(100)$ & $97(100)$ & $66(100)$ & $32(100)$ & $21(100)$ & $8(100)$ & --- \\
\hline \multicolumn{10}{|l|}{178} \\
\hline
\end{tabular}


Reason: the reason for the first readmission

181 Interval: the interval between the index admission and the first readmission

182 All data reported by $\mathrm{N}(\%)$ except for ${ }^{\mathrm{A}}$ reported by $\mathrm{N}$ only.

183 Sum in all readmission groups: readmissions 1-15th.

184

Furthermore, readmission events mostly occurred without any previous medical planning. Almost all the readmissions happened because patients suffered from either additional or prolonged

187 complications resulting from the primary trauma injury that had been received in combat. Table 2

188 presents information about the planning status of each readmission event, and expresses the

189 relationship between the index admission and the next readmissions.

\section{Table 2. Readmission condition and Relation of readmission to the} 191 index admission for each readmission.

\begin{tabular}{|c|c|c|c|c|c|}
\hline \multirow{3}{*}{$\begin{array}{l} \\
\\
\\
\text { Readmission } \\
\text { Number }\end{array}$} & \multicolumn{2}{|c|}{ Readmission Condition } & \multicolumn{2}{|l|}{ Relationship } & \multirow[b]{2}{*}{ Total } \\
\hline & N (\%) & $\mathrm{N}(\%)$ & \begin{tabular}{|c|}
$\begin{array}{c}\text { Primary } \\
\text { injury } \\
\text { complications }\end{array}$ \\
$\mathrm{N}(\%)$ \\
\end{tabular} & $\begin{array}{c}\text { Unrelated } \\
\text { to first } \\
\text { admission } \\
\mathrm{N}(\%)\end{array}$ & \\
\hline & & & & & \\
\hline 1 & $231(29.8)$ & $544(70.2)$ & $739(95.4)$ & $36(4.6)$ & $775(100)$ \\
\hline 2 & 101(30.7) & $228(69.3)$ & $313(95.12)$ & $16(4.88)$ & $329(100)$ \\
\hline 3 & $44(26.7)$ & $121(73.3)$ & 161(97.57) & $4(2.43)$ & $165(100)$ \\
\hline 4 & $24(24.7)$ & $73(75.3)$ & $92(94.8)$ & $5(5.2)$ & $97(100)$ \\
\hline 5 & $18(27.3)$ & $48(72.7)$ & $63(95.45)$ & $3(4.55)$ & $66(100)$ \\
\hline 6 & $8(25)$ & $24(75)$ & $29(90.62)$ & $3(9.38)$ & $32(100)$ \\
\hline 7 & $4(19)$ & $17(81)$ & $19(90.48)$ & $2(9.52)$ & $21(100)$ \\
\hline 8 & $1(12.5)$ & $7(87.5)$ & $7(87.5)$ & $1(12.5)$ & $8(100)$ \\
\hline 9 & $0(0.0)$ & $3(100)$ & $3(100)$ & $0(0.0)$ & $3(100)$ \\
\hline 10 & $1(50)$ & $1(50)$ & $2(100)$ & $0(0.0)$ & $2(100)$ \\
\hline 11 & $0(0.0)$ & $1(100)$ & $1(100)$ & $0(0.0)$ & $1(100)$ \\
\hline 12 & $0(0.0)$ & $1(100)$ & $1(100)$ & $0(0.0)$ & $1(100)$ \\
\hline 13 & $0(0.0)$ & $1(100)$ & $1(100)$ & $0(0.0)$ & $1(100)$ \\
\hline 14 & $0(0.0)$ & $1(100)$ & $1(100)$ & $0(0.0)$ & $1(100)$ \\
\hline 15 & $0(0.0)$ & $1(100)$ & $1(100)$ & $0(0.0)$ & $1(100)$ \\
\hline
\end{tabular}


193 In terms of the interval between the date of discharge from the index admission and the subsequent

194 readmission event, 373 patients were readmitted to the hospital within less than a month, and 221,

19578,62 , and 41 cases were referred to the hospital between 1-3, 3-6, 6-12 months, and 1 year after

196 the index admission, respectively. Table 3 lists the data about the reason for the index admission

197 categorized based on the interval between the first and second admissions explained above. 


\section{Table 3. The reason for the first readmission categorized based on the 212 interval between the date of discharge from the index admission and the 213 first readmission.}

\begin{tabular}{|c|c|c|c|c|c|c|}
\hline Reason $=$ Interval & $\begin{array}{c}\leq 30 \text { days } \\
\mathrm{N}(\%)\end{array}$ & $\begin{array}{c}31 \text { days } \leq<90 \\
\text { days } \\
N(\%)\end{array}$ & $\begin{array}{c}90 \leq \text { days }<180 \\
\text { N }(\%)\end{array}$ & $\begin{array}{c}180 \leq \text { days }<1 \text { year } \\
\text { N }(\%)\end{array}$ & $\begin{array}{l}1 \text { year } \\
\mathrm{N}(\%)\end{array}$ & $\begin{array}{r}\text { Total } \\
\text { N }(\%)\end{array}$ \\
\hline Wound infections & $72(19.3)$ & $17(7.7)$ & $7(9)$ & $4(6.5)$ & $1(2.4)$ & $101(13)$ \\
\hline Gastrointestinal & $15(4)$ & $3(1.4)$ & $3(3.8)$ & $3(4.8)$ & $1(2.4)$ & $25(3.2)$ \\
\hline Amputation stump complications & $9(2.4)$ & $3(1.4)$ & $2(2.6)$ & $0(0.0)$ & $0(0.0)$ & $14(1.8)$ \\
\hline Movement restrictions & $24(6.4)$ & $24(10.9)$ & $6(7.7)$ & $7(11.3)$ & $3(7.3)$ & $64(8.3)$ \\
\hline Deformity in head and neck & $28(7.5)$ & $22(10)$ & $4(5.1)$ & $5(8.1)$ & $4(9.8)$ & $63(8.1)$ \\
\hline After care for surgery & $5(1.3)$ & $4(1.8)$ & $0(0.0)$ & $1(1.6)$ & $0(0.0)$ & $10(1.3)$ \\
\hline Respiratory & $5(1.3)$ & $1(0.5)$ & $1(1.3)$ & $0(0.0)$ & $0(0.0)$ & $7(0.9)$ \\
\hline Ophthalmic & $6(1.6)$ & $4(1.8)$ & $1(1.3)$ & $0(0.0)$ & $2(4.9)$ & $13(1.7)$ \\
\hline New trauma & $4(1.1)$ & $4(1.8)$ & $2(2.6)$ & $4(6.5)$ & $4(9.8)$ & $18(2.3)$ \\
\hline Graft & $21(5.6)$ & $6(2.7)$ & $2(2.6)$ & $1(1.6)$ & $2(4.9)$ & $32(4.1)$ \\
\hline Hearing & $5(1.3)$ & $10(4.5)$ & $2(2.6)$ & $3(4.8)$ & $4(9.8)$ & $24(3.1)$ \\
\hline Foreign Body & $30(8)$ & $11(5)$ & $5(6.4)$ & $2(3.2)$ & $4(9.8)$ & $52(6.7)$ \\
\hline Osteomyelitis & $3(0.8)$ & $1(0.5)$ & $1(1.3)$ & $1(1.6)$ & $0(0.0)$ & $6(0.8)$ \\
\hline Urinary & $3(0.8)$ & $0(0.0)$ & $0(0.0)$ & $3(4.8)$ & $2(4.9)$ & $8(1)$ \\
\hline Closure of ostomi & $4(1.1)$ & $10(4.5)$ & $4(5.1)$ & $0(0.0)$ & $0(0.0)$ & $18(2.3)$ \\
\hline Bedsore & $7(1.9)$ & $3(1.4)$ & $1(1.3)$ & $3(4.8)$ & $1(2.4)$ & $15(1.9)$ \\
\hline Deep vein thrombosis (DVT) & $7(1.9)$ & $0(0.0)$ & $0(0.0)$ & $0(0.0)$ & $0(0.0)$ & $7(0.9)$ \\
\hline Laryngopathy & $0(0.0)$ & $1(0.5)$ & $1(1.3)$ & $0(0.0)$ & $0(0.0)$ & $2(0.3)$ \\
\hline Neurologic & $4(1.1)$ & $1(0.5)$ & $0(0.0)$ & $1(1.6)$ & $0(0.0)$ & $6(0.8)$ \\
\hline Cardiologic & $1(0.3)$ & $0(0.0)$ & $0(0.0)$ & $0(0.0)$ & $1(2.4)$ & $2(0.3)$ \\
\hline Surgical device remove & $19(5.1)$ & $34(15.4)$ & $9(11.5)$ & $6(9.7)$ & $2(4.9)$ & $70(9)$ \\
\hline Pain & $42(11.3)$ & $16(7.2)$ & $7(9)$ & $7(11.3)$ & $3(7.3)$ & $75(9.7)$ \\
\hline Non-union of fracture & $18(4.8)$ & $26(11.8)$ & $14(17.9)$ & $5(8.1)$ & $1(2.4)$ & $64(8.3)$ \\
\hline Vascular & $8(2.1)$ & $0(0.0)$ & $0(0.0)$ & $0(0.0)$ & $0(0.0)$ & $8(1)$ \\
\hline Psychiatric & $13(3.5)$ & $13(5.9)$ & $2(2.6)$ & $3(4.8)$ & $3(7.3)$ & $34(4.4)$ \\
\hline Wound unhealing & $20(5.4)$ & $3(1.4)$ & $3(3.8)$ & $0(0.0)$ & $2(4.9)$ & $28(3.6)$ \\
\hline Hernia & $0(0.0)$ & $4(1.8)$ & $1(1.3)$ & $3(4.8)$ & $1(2.4)$ & $9(1.2)$ \\
\hline Total & $373(100)$ & $221(100)$ & $78(100)$ & $62(100)$ & $41(100)$ & $775(100)$ \\
\hline
\end{tabular}


244 The number of patients belonging to the group of multiple readmissions outweighed those in the

245 single readmission group only in the subgroup of 8-30 days of LOS. For the first readmission 246 event, the number of patients hospitalized 1-6 days before discharge reached 603.

Table 4: Frequency of each LOS subcategory between patients with single readmission and those with multiple readmissions

\begin{tabular}{|l|l|l|l|l|}
\hline \multirow{2}{*}{} & \multicolumn{2}{|c|}{ Single Readmission } & \multicolumn{2}{c|}{$\begin{array}{c}\text { Multiple } \\
\text { Readmission }\end{array}$} \\
\cline { 2 - 5 } & $\begin{array}{c}\text { Frequency } \\
(\mathrm{N})\end{array}$ & $\begin{array}{c}\text { Valid percent } \\
(\%)\end{array}$ & $\begin{array}{c}\text { Frequency } \\
(\mathrm{N})\end{array}$ & $\begin{array}{c}\text { Valid } \\
\text { percent } \\
(\%)\end{array}$ \\
\hline $\begin{array}{c}\text { Length of the } \\
\text { first stay in } \\
\text { hospital }\end{array}$ & \multicolumn{4}{|c|}{} \\
\hline $0-3$ days & 172 & 39.9 & 109 & 31.7 \\
\hline $4-7$ days & 120 & 27.8 & 87 & 25.3 \\
\hline $8-30$ days & 116 & 26.9 & 129 & 37.5 \\
\hline$>30$ days & 23 & 5.3 & 19 & 5.5 \\
\hline
\end{tabular}


247 In addition, the great majority of the investigated combat-related injuries were penetrating $(\mathrm{N}=639$,

$24882.5 \%)$, followed by blunt ( $\mathrm{N}=97,12.5 \%)$. Most of these injuries were caused by fragments from

249 explosive munitions rather than from bullets fired by a gun. The most injured part of the body was

250 the extremities $(\mathrm{N}=360,46.5 \%)$, followed by the head and neck $(\mathrm{N}=175,22.6 \%)$ and the abdomen

251 and pelvis $(\mathrm{N}=106,13.7 \%)$, in that order. Overall, patients more frequently had a maximum AIS

252 of $4(\mathrm{~N}=332,42.8 \%)$, followed closely by a score of 5-6 ( $\mathrm{N}=298,38.5 \%)$.

253 Logistic regression was performed to study the relationship between the number of comorbidities,

254 the type and mechanism of trauma, the most involved part of the body, LOS, maximum AIS, ISS,

255 the type of operation (if any), patients' need for blood transfusion, side effects (all in terms of the

256 index admission), ICU stay, and the dependent variables of interest. There was no significant

257 relationship between the number of comorbidities, the type and mechanism of trauma, ISS, the

258 most involved part of the body, the type of operation, side effects, and ICU stay and multiple

259 readmissions (data not shown), although the other predictors showed a statistically significant

260 association with multiple readmissions at least in one subcategory. Table 5 gives the results of

261 regression analysis in terms of the odds ratio, P-value, and confidence interval. Moreover, total

262 readmission days was associated with some of the above-mentioned independent variables,

263 including the LOS, the type of trauma, the most involved part of the body, maximum AIS, ISS,

264 patients' need for blood transfusion, and side effects. Table 6 summarizes these results. 
Table 5. Association of multiple readmissions with LOS, max AIS, ISS, side effect, and 268 patient's need for blood transfusion.

\begin{tabular}{|l|c|c|c|c|}
\hline \multicolumn{1}{|c|}{ Variable } & OR & Lower CI & Upper CI & P-value \\
\hline LOS (reference: 1-3 days) & 1.14 & 0.79 & 1.65 & 0.47 \\
\hline 4-7 days & 1.75 & 1.24 & 2.48 & 0.001 \\
\hline 8-30 days & 1.3 & 0.67 & 2.5 & 0.42 \\
\hline$>$ 30 days & 0.9 & 0.45 & 1.8 & 0.08 \\
\hline Max AIS (reference: 1-2) & 1.1 & 0.68 & 1.96 & 0.72 \\
\hline 3 & 1.95 & 1.09 & 3.46 & 0.02 \\
\hline 4 & 1.15 & 0.75 & 1.77 & 0.52 \\
\hline 5-6 & 1.69 & 1.02 & 2.8 & 0.039 \\
\hline ISS (reference: $<9$ ) & 2.24 & 1.46 & 3.44 & $<0.001$ \\
\hline 9-15 & 1.53 & 1.07 & 2.19 & 0.019 \\
\hline 16-24 & 1.9 & 1.25 & 2.85 & 0.002 \\
\hline$>24$ & \multicolumn{5}{|l}{} \\
\hline Side effect ${ }^{+}$(reference: no side effect) & \multicolumn{5}{|l}{} \\
\hline $\begin{array}{l}\text { Wound infection } \\
\text { Patient's need for blood transfusion (no vs. } \\
\text { yes) }\end{array}$ & \multicolumn{5}{|l}{} \\
\hline
\end{tabular}

LOS: length of stay in hospital, OR: odd ratio, CI: confidence interval, Max AIS: maximum amount of the abbreviated injury scale, ISS: Injury Severity Score.

273 +: Data not shown for other categories of side effect variable, as there was not any significant relationship with other subgroups of the variable. 
Table 6. Association of total days of readmissions with LOS, the most involved part of body, max AIS, ISS, side effect, patient's need for blood transfusion.

\begin{tabular}{|l|c|c|c|c|}
\hline Variable & OR & Lower CI & Upper CI & P-value \\
\hline LOS (reference: 1-3 days) & 1.11 & 0.74 & 1.65 & 0.61 \\
\hline 4-7 days & 2.42 & 1.68 & 3.48 & $<0.001$ \\
\hline 8-30 days & 4.31 & 2.19 & 8.46 & $<0.001$ \\
\hline >30 days & 1.1 & 0.57 & 2.2 & 0.74 \\
\hline The most involved part of body (reference: head and neck) \\
\hline Thorax & 2.09 & 1.28 & 3.42 & 0.003 \\
\hline Abdomen and pelvic & 0.86 & 0.59 & 1.26 & 0.46 \\
\hline Extremities & 0.56 & 0.31 & 1.001 & 0.05 \\
\hline External & 0.7 & 0.32 & 1.59 & 0.42 \\
\hline Max AIS (reference: 1-2) & 1.28 & 0.68 & 2.41 & 0.44 \\
\hline 3 & 2.89 & 1.54 & 5.42 & 0.001 \\
\hline 4 & 1.54 & 0.95 & 2.5 & 0.079 \\
\hline 5-6 & 1.86 & 1.07 & 3.24 & 0.027 \\
\hline ISS (reference: $<9$ ) & 3.8 & 2.37 & 6.09 & $<0.001$ \\
\hline 9-15 & \multicolumn{5}{|l|}{} \\
\hline 16-24 & 2.56 & 1.78 & 3.68 & $<0.001$ \\
\hline >24 & 4.1 & 2.68 & 6.29 & $<0.001$ \\
\hline Side effect ${ }^{+}$(reference: no side effect) \\
\hline Wound infection \\
\hline $\begin{array}{l}\text { Patient's need for blood transfusion } \\
\text { no vs. yes) }\end{array}$
\end{tabular}

295

296

297

298

299

300

301

302

303 It seems that a patient who stayed 8-30 days in the hospital for initial care had a 1.75-time higher

304 chance for multiple readmissions than a patient who stayed $<3$ days during the index admission.

305 Max AIS exerted another effect on multiple readmissions; those who had a maximal degree of 306 AIS, i.e., 5-6, had about twice the chance for more than one readmission event compared to those 307 with the minimum value of AIS, i.e., 1-2. The influence of ISS was also considerable; 1.69 and

LOS: length of stay in hospital, OR: odd ratio, CI: confidence interval, Max AIS: maximum amount of the abbreviated injury scale, ISS: Injury Severity Score.

+: Data not shown for other categories of side effect variable, as there was not any significant relationship with other subgroups of the variable. 
309 in comparison to those with ISS $<9$, respectively. Also, side effect was a statistically significant

310 variable: Patients who developed wound infection as the side effect had a 1.53-time higher chance

311 for multiple readmissions compared to those without any side effect, although such a significant

312 relationship was not detected in other subgroups of side effect. Similarly, in terms of multiple

313 readmissions, the outcome was about twice worse in patients who required blood transfusion

314 during the index admission.

315 It was also noted that patients with 8-30 and $>30$ days of LOS during the index admission had a

316 2.42- and 4.31-time higher chance for more than a week of readmission, respectively. The most

317 involved part of the body was relevant, too: Patients receiving the most serious injuries to the

318 abdomen and pelvis were nearly twice more likely to stay in the hospital for more than a week

319 during readmissions than those sustaining a head and neck injury. Furthermore, max AIS

320 significantly affected the period of readmission events; patients who had a maximum AIS, i.e., 5-

3216 , had an about three-time higher chance for longer readmissions in total compared to patients with

322 an AIS of 1-2. As for ISS, we found that patients with an ISS score of 16-24 and >24 had a 1.86-

323 and 3.8-time higher chance of staying $>7$ days in the hospital within the readmission course,

324 respectively. The odds ratio for side effects showed that patients who developed wound infection

325 were 2.56 times more likely to stay longer in the hospital than those who did not develop any side

326 effects. Furthermore, the odds of a long readmission period for patients who needed blood

327 transfusion were 4.1 times higher than those for the reference group.

328 The results of the chi-square test revealed an insignificant relationship between the type of trauma 329 and the mechanism of trauma on the one hand, and admission to the intensive care unit (ICU) and 330 side effects on the other hand. Nevertheless, both the type and mechanism of trauma were 
331 significantly related to the patients' need for transfusion ( $\mathrm{P}=0.001$ and $\mathrm{P}=0.008$, respectively). The

332 type and mechanism of trauma also showed significant relationships with operation, maximum

333 AIS, ISS, and LOS ( $\mathrm{P}<0.001$ for all the variables). Moreover, the most involved part of the body

334 had significant correlations with all the above-mentioned variables $(\mathrm{P}<0.001)$.

\section{Discussion}

336 Collectively, in the investigated surviving wounded population, extremity and head and neck

337 injuries accounted for $46.5 \%$ and $22.6 \%$ of all the wounds, respectively. This pattern is similar to

338 the observations from previous wars, e.g. Afghanistan or Chechnya War $(1,11)$. The regression

339 analysis revealed no significant correlation between either multiple readmissions or total days of

340 readmissions and the number of comorbidities, mechanism of trauma, type of operation, and ICU

341 stay. There was a significant relationship between multiple readmissions and total readmission

342 days and some variables such as LOS, max AIS, ISS, side effects, and blood transfusion. The

343 predictor of a significant effect only on the total days of readmission was the most involved part

344 of the body.

345 Here, we focused on multiple readmissions in a one-year period and their total length since we

346 believed that only by comparing single and multiple readmissions can the relevant explanatory

347 factor be determined. This approach also enabled the identification of high-risk patients who are

348 the most appropriate target group for reducing the overall number of readmission events. To date,

349 numerous studies have examined 30-day readmission for various severe diseases and suggested

350 that it is associated with the male $\operatorname{sex}(\mathrm{OR}=1.83, \mathrm{P}=0.02)$, ICU stay ( $\mathrm{OR}=2.5, \mathrm{P}=0.049)$, $\mathrm{LOS}(4)$,

351 comorbidity score (17), and different socioeconomic factors (18), although similar studies are rare

352 in military settings. 
353 Given that the present study examined readmission occurrence resulting from combat-related

354 injuries, we noticed some similarities and differences in the results. First of all, almost all our

355 participants were young and without any underlying chronic disease or comorbidity, indicating

356 considerable potential for lowering readmissions after a combat injury in such circumstances.

357 Secondly, there was no difference between different groups of patients in this study in terms of

358 ICU stay. It seems that ICU stay during the initial admission is not a significant explanatory factor

359 here. In addition to very different causes for the index admission, another explanation could be the

360 fact that our sample was young and we examined a much longer readmission period. Therefore, it

361 is likely that the quality of hospital care and readmissions was affected by various factors in

362 military hospitals compared to regular ones.

363 Not surprisingly, our findings revealed that the severity of injuries defined by AIS and ISS had

364 important impacts on multiple readmissions and total days of readmission. The most severe

365 injuries led to a considerably higher risk for not only recurrent but also prolonged readmission

366 events. On the other hand, it has been well established that the extreme severity of the disease is

367 associated with high resource use outliers $(18,19)$. Given these, the findings imply that patients

368 with severe injury or, perhaps, with severe illness might require high-quality care for longer

369 durations, especially as part of the initial hospital inpatient stay. In these patients, premature

370 discharge from the index admission may lead to subsequent readmissions and its associated costs,

371 and should thus be avoided. Even though these factors are not alterable, severity indices may be

372 helpful in identifying high-risk groups of patients.

373 We also found that longer LOS within the index admission puts patients at risk of multiple and

374 longer readmission events. This result is partially consistent with some other studies on internal

375 medicine patients conducted in civilian settings $(4,17,20)$, which examined a much shorter post- 
376 discharge period than the present study. Still, a longer LOS seems to be an important factor for

377 predicting the risk of repeated future readmissions. Although there are some concerns that an

378 earlier hospital discharge may result in higher readmission rates, a reduction in LOS has not shown

379 any negative effect on the 30-day hospital readmission rate (4). A possible explanation can be that

380 improvement in LOS might not necessarily affect the quality of hospital service. Such

381 improvements can be achieved by adopting better procedures for discharge from the hospital (4).

382 Accordingly, a reduction in LOS can be an appropriate measure for preventing repeated

383 readmissions.

384 Contrary to our expectations, the type of operation was not significantly correlated with the

385 frequency and duration of readmission events. It is more likely that this factor should indirectly

386 exert its effect through other variables such as the need for blood transfusion, AIS, ISS, and LOS.

387 In fact, based on the results of the chi-square test, the type of operation was correlated with these

388 variables $(\mathrm{P}<0.001)$.

389 Moreover, the regression analysis found that side effects might have an impact on the duration and

390 frequency of future re-hospitalizations. Still, this effect was only significant in the subgroup of

391 patients who developed wound infection, and was inconsistent among other patient subgroups. It

392 seems that wound infections can impose great demands on hospital resources by increasing

393 readmission events and their duration. This outcome is in line with the literature that has

394 determined trauma-related infections as a major contributor to substantial morbidity among

395 wounded military personnel. Given the observation that wound infections were the primary cause

396 of hospitalization, this finding highlights the importance of considering both treatment and

397 preventive measures equally. These measures can include improvement of patients' immune

398 system (21), prescription of effective antibiotics (22), and treatment timing (23). 
399 The last factor of significant influence on both dependent variables was the patients' need for blood

400 transfusion. In the management of combat-related injuries, blood transfusion is essential because

401 uncontrollable hemorrhage is the major cause of possibly preventable casualties $(24,25)$. Our

402 results confirm that the need for blood transfusion is linked to a poor prognosis in trauma combat

403 patients regarding the occurrence of repeated and longer readmissions. Among all the investigated

404 factors, the most involved part of the body was the only factor which correlated with total

405 readmission days but not with multiple readmissions. It seems that injury to the head and neck

406 leads to a higher risk of longer readmission courses.

407 Briefly, our results provide insight into what possible relationships exist between LOS and 408 readmission and the investigated variables. Among the statistically significant variables

409 influencing multiple readmissions, ISS $>24$ led to the highest risk. Regarding total days of 410 readmission, $\operatorname{LOS}>30$ days and blood transfusion had the largest effects, respectively.

411 Our study had some limitations. The first was the retrospective design of the study, in which almost

412 all the data were collected from patient records. The second was the fact that the sample was

413 collected from only one center. Third, we did not evaluate factors such as social determinants and

414 having someone to help at home following discharge. We believe that our results should be

415 confirmed in studies with larger samples which examine a wider range of possible risk factors.

\section{Conclusion}

417 Differentiating between preventable and non-preventable readmissions might provide a basis for 418 the development of effective strategies to reduce the readmission rate in military settings. To this 419 end, high-risk patients for multiple readmissions must be first determined. Referring to the data, 420 we can conclude that the severity of the injury, the LOS in the hospital, developing wound 
421 infection, injury to the abdomen and pelvis, and the need for blood transfusion within the index

422 admission appear to be associated with an increased risk of multiple and longer readmission events.

423 Identification of these risk factors can pave the way for attending to patients who have them and,

424 thus, for promoting the quality of hospital care. The overall outcome will be more effective 425 management of combat-related injuries and their related medical costs, which may benefit both 426 patients and society.

\section{Declarations}

428 Ethical approval and Consent to participate: This study has ethical approval from Iran national

429 committee for ethics in biomedical research (Ethics committee code: IR.BMSU.REC.1398.186)

430 All the information used in the study was extracted from the records of patients who have consent

431 to participate in the study

432 Consent for publication: All participants in the study have consent for publication of their disease 433 information.

434 Availability of data and materials: The datasets generated and analysed during the current study 435 are not publicly available because the information used in the study is related to the military 436 personnel and access to their information is a security issue but are available from the 437 corresponding author on reasonable request.

438 Competing interests: The authors declare that they have no competing interests.

439 Funding: Funding information is not applicable / No funding was received.

440 Authors Contributions: Hamid Reza Gharehchahi and Sadrollah Mahmoudi wrote the main 
441 text of the manuscript. Hadi Khoshmohabat designed the study and collaborated on data

442 collection. Hamid Reza Javadzadeh designed the figures and tables. Amin

443 Mohamadrezapourzare analyzed the data.

444 Acknowledgements: We are grateful to our colleagues working at the military hospital who helped 445 us collect the data.

446 Authors information: Hamid Reza Gharehchahi ${ }^{1}$, Sadrollah Mahmoudi ${ }^{2 *}$, Hadi Khoshmohabat ${ }^{1}$,

447 Hamid Reza Javadzadeh ${ }^{1}$, Amin Mohamadrezapourzare ${ }^{1}$

448 1. Trauma Research Center, Baqiyatallah University of Medical Sciences, Tehran, Iran

449 2. Emergency Department, Baqiyatallah University of Medical Sciences, Tehran, Iran

$450 \quad$ *Corresponding author: Sadrollah Mahmoudi ${ }^{1}$, Emergency Department, Baqiyatallah

451 University of Medical Sciences, Tehran, Iran

452 Phone/Fax: 00982188053766, E-mail address: Mahmoudisadrollah@gmail.com 453

\section{References}

458 1. Conventional Warfare: Ballistic, Blast, and Burn Injuries (Textbook of Military Medicine 459 Series on Combat Casualty Care, Part 1 Volume 5): Ronald F. Bellamy, Russ Zajtchuk, 460 Ronald F. Bellamy, Russ Zajtchuk: 9780160591310: Amazon.com: Books [Internet]. 461 [cited 2020 Dec 18]. Available from: https://www.amazon.com/Conventional-Warfare$462 \quad$ Ballistic-Injuries-Textbook/dp/0160591317 
463 2. Kim HM, Eisenberg D, Ganoczy D, Hoggatt K, Austin KL, Downing K, et al. Examining 464 the relationship between clinical monitoring and suicide risk among patients with depression: Matched case-control study and instrumental variable approaches. Health Serv Res [Internet]. 2010 Oct [cited 2020 Dec 18];45(5 PART 1):1205-26. Available from: https://pubmed.ncbi.nlm.nih.gov/20609017/

468 3. Prince JD, Akincigil A, Hoover DR, Walkup JT, Bilder S, Crystal S. Substance Abuse and Hospitalization for Mood Disorder among Medicaid Beneficiaries. Am J Public Health [Internet]. 2009 Jan 1 [cited 2020 Dec 18];99(1):160-7. Available from: https://pubmed.ncbi.nlm.nih.gov/19008505/

472 4. Kaboli PJ, Go OT, Hockenberry J, Glasgow JM, Johnson SR, Rosenthal GE, et al. Associations between reduced hospital length of stay and 30-day readmission rate and mortality: 14-year experience in 129 veterans affairs hospitals. Ann Intern Med. 2012;157(12):837-45.

5. Worzala C, Pettengill J, Ashby J. Challenges and opportunities for medicare's original prospective payment system [Internet]. Vol. 22, Health Affairs. Health Aff (Millwood); 2003 [cited 2020 Dec 18]. p. 175-82. Available from: https://pubmed.ncbi.nlm.nih.gov/14649444/

6. Bernheim SM, Grady JN, Lin Z, Wang Y, Wang Y, Savage S V., et al. National patterns of risk-standardized mortality and readmission for acute myocardial infarction and heart failure update on publicly reported outcomes measures based on the 2010 release. Circ Cardiovasc Qual Outcomes [Internet]. 2010 Sep [cited 2020 Dec 18];3(5):459-67. Available from: https://pubmed.ncbi.nlm.nih.gov/20736442/

7. Jha AK, Orav EJ, Epstein AM. Public Reporting of Discharge Planning and Rates of 486 Readmissions. N Engl J Med [Internet]. 2009 Dec 31 [cited 2020 Dec 18];361(27):263745. Available from: https://pubmed.ncbi.nlm.nih.gov/20042755/

488 8. Van Walraven C, Bennett C, Jennings A, Austin PC, Forster AJ. Proportion of hospital 489 readmissions deemed avoidable: A systematic review. CMAJ [Internet]. 2011 Apr 19 [cited 2020 Dec 18];183(7). Available from: https://pubmed.ncbi.nlm.nih.gov/21444623/ 
491 9. Upadhyay S, Stephenson AL, Smith DG. Readmission Rates and Their Impact on 492 Hospital Financial Performance: A Study of Washington Hospitals. Inq (United States) 493 [Internet]. 2019 Jul 1 [cited 2020 Dec 18];56. Available from:

494 https://pubmed.ncbi.nlm.nih.gov/31282282/

495 10. Centers for Medicare. Medicare Program; hospital inpatient prospective payment systems 496 for acute care hospitals and the long-term care hospital prospective payment system changes and FY2011 rates; provider agreements and supplier approvals; and hospital conditions of participation for rehabilitation and respiratory care services; Medicaid program: accreditation for providers of inpatient psychiatric services. Final. Fed Regist.

501 11. Champion HR, Bellamy RF, Roberts CP, Leppaniemi A. A profile of combat injury. J Trauma - Inj Infect Crit Care. 2003;54(5 SUPPL.).

503 12. Van Walraven C, Jennings A, Forster AJ. A meta-analysis of hospital 30-day avoidable readmission rates. J Eval Clin Pract [Internet]. 2012 Dec [cited 2020 Dec 18];18(6):12118. Available from: https://pubmed.ncbi.nlm.nih.gov/22070191/

506 13. Ross JS, Chen J, Lin Z, Bueno H, Curtis JP, Keenan PS, et al. Recent national trends in readmission rates after heart failure hospitalization. Circ Hear Fail [Internet]. 2010 Jan [cited 2020 Dec 18];3(1):97-103. Available from: https://pubmed.ncbi.nlm.nih.gov/19903931/

510 14. Elixhauser A, Steiner C, Harris DR, Coffey RM. Comorbidity Measures for Use with 511 Administrative Data. Med Care [Internet]. 1998 [cited 2020 Dec 18];36(1):8-27.

512 Available from: https://pubmed.ncbi.nlm.nih.gov/9431328/

513 15. Abbreviated Injury Scale (AIS) - Association for the Advancement of Automotive 514 Medicine [Internet]. [cited 2020 Dec 18]. Available from:

515 https://www.aaam.org/abbreviated-injury-scale-ais/

516 16. The injury severity score: a method for describing patients with multiple injuries and 517 evaluating emergency care - PubMed [Internet]. [cited 2020 Dec 18]. Available from: 
https://pubmed.ncbi.nlm.nih.gov/4814394/

519 17. Kaya S, Sain Guven G, Aydan S, Toka O. Predictors of hospital readmissions in internal medicine patients: Application of Andersen's Model. Int J Health Plann Manage [Internet]. 2019 Jan 1 [cited 2020 Dec 18];34(1):370-83. Available from: https://pubmed.ncbi.nlm.nih.gov/30221793/

523 18. [Are extra costs generated by patients justifiable? Methodology and results from a study 524 carried out in a Belgian general hospital] - PubMed [Internet]. [cited 2020 Dec 18]. 525 Available from: https://pubmed.ncbi.nlm.nih.gov/20677665/

526 19. Pirson M, Dramaix M, Leclercq P, Jackson T. Analysis of cost outliers within APR-DRGs in a Belgian general hospital: Two complementary approaches. Health Policy (New York) [Internet]. 2006 Mar [cited 2020 Dec 18];76(1):13-25. Available from: https://pubmed.ncbi.nlm.nih.gov/15921818/

530 20. Blanc AL, Fumeaux T, Stirnemann J, Lozeron ED, Ourhamoune A, Desmeules J, et al. 531 Development of a predictive score for potentially avoidable hospital readmissions for general internal medicine patients. PLoS One [Internet]. 2019 Jul 1 [cited 2020 Dec 18];14(7). Available from: https://pubmed.ncbi.nlm.nih.gov/31306461/

534 21. Owens CD, Stoessel K. Surgical site infections: epidemiology, microbiology and 535 prevention. J Hosp Infect [Internet]. 2008 Nov [cited 2020 Dec 18];70(SUPPL. 2):3-10. Available from: https://pubmed.ncbi.nlm.nih.gov/19022115/

537 22. Waltz PK, Zuckerbraun BS. Surgical site infections and associated operative 538 characteristics. Surg Infect (Larchmt) [Internet]. 2017 May 1 [cited 2020 Dec 18];18(4):447-50. Available from: https://pubmed.ncbi.nlm.nih.gov/28448197/

540 23. Chen SH, Chen WJ, Wu MH, Liao JC, Fu CJ. Postoperative infection in patients 541 undergoing posterior lumbosacral spinal surgery: A pictorial guide for diagnosis and early 542 treatment. Clin Spine Surg [Internet]. 2018 Jul 1 [cited 2020 Dec 18];31(6):225-38.

$543 \quad$ Available from: https://pubmed.ncbi.nlm.nih.gov/29595747/

544 24. Analyses of battle casualties by weapon type aboard U.S. Navy warships - PubMed 
545 [Internet]. [cited 2020 Dec 18]. Available from:

546 https://pubmed.ncbi.nlm.nih.gov/1603403/

547 25. USS Franklin and the USS Stark--recurrent problems in the prevention and treatment of 548 naval battle casualties - PubMed [Internet]. [cited 2020 Dec 18]. Available from:

549 https://pubmed.ncbi.nlm.nih.gov/2499833/

550 
Figures

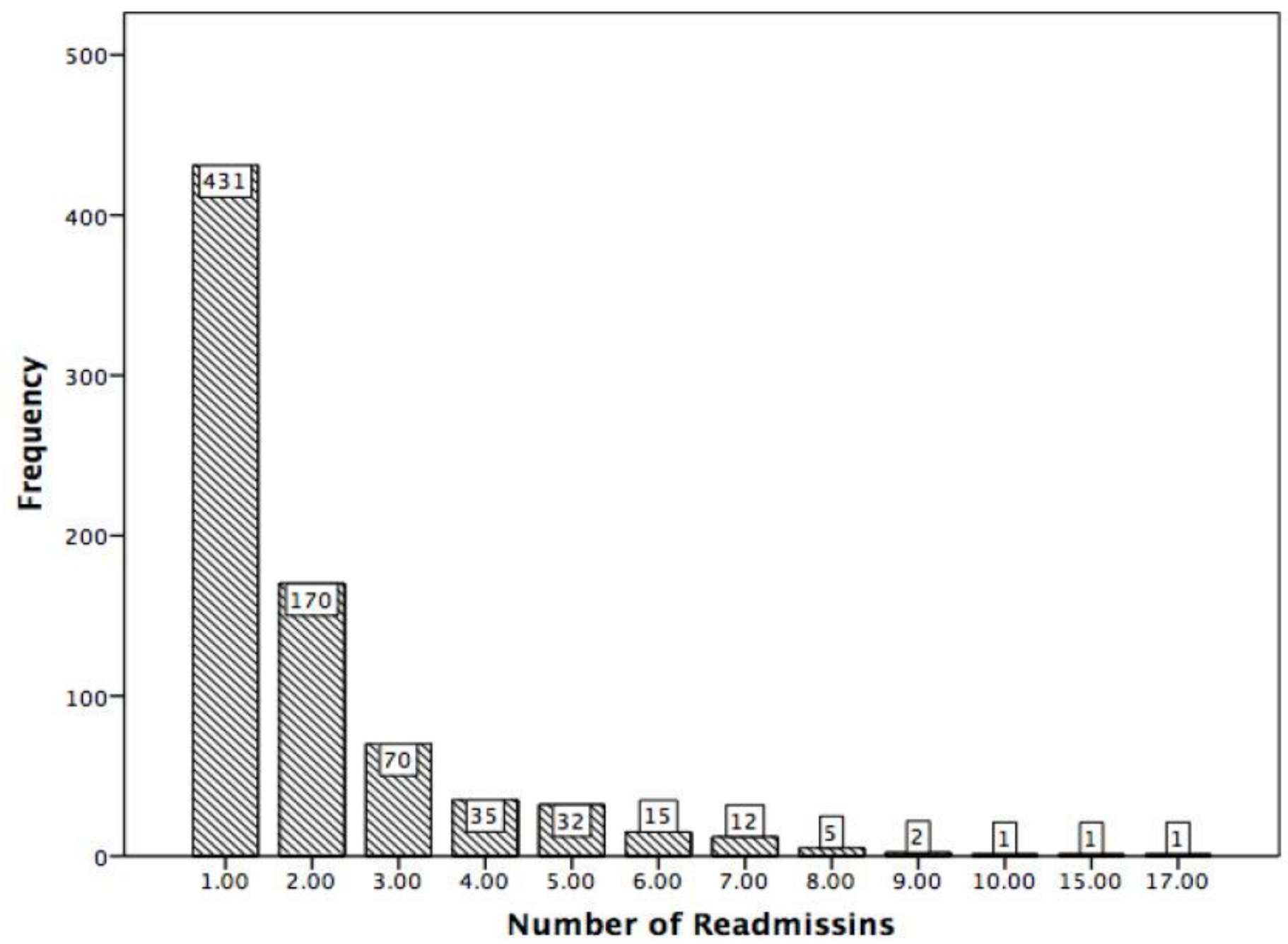

Figure 1

Frequency of patients based on the number of readmission events 